\title{
Les grands discours parlementaires de la Révolution de Mirabeau à Robespierre
}

Jean-Luc Chappey

\section{(2) OpenEdition \\ 1 Journals}

Édition électronique

URL : https://journals.openedition.org/ahrf/2228

DOI : 10.4000/ahrf.2228

ISSN : 1952-403X

Éditeur :

Armand Colin, Société des études robespierristes

Édition imprimée

Date de publication : 1 septembre 2005

Pagination : 197-198

ISSN : 0003-4436

Référence électronique

Jean-Luc Chappey, "Les grands discours parlementaires de la Révolution de Mirabeau à

Robespierre », Annales historiques de la Révolution française [En ligne], 341 I juillet-septembre 2005, mis en ligne le 27 avril 2006, consulté le 22 avril 2022. URL : http://journals.openedition.org/ahrf/2228 ; DOl : https://doi.org/10.4000/ahrf.2228

Ce document a été généré automatiquement le 22 avril 2022.

Tous droits réservés 


\title{
Les grands discours parlementaires de la Révolution de Mirabeau à Robespierre
}

\author{
Jean-Luc Chappey
}

\section{RÉFÉRENCE}

Les grands discours parlementaires de la Révolution de Mirabeau à Robespierre, préface de Jean-Louis Debré, textes présentés par Guy Chaussinand-Nogaret, Paris, Armand Colin, 2005, 272 p., ISBN 2-200-26831-9, 20 e.

1 Après deux volumes consacrés à la III ${ }^{e}$ République, la collection "d'Histoire parlementaire ", dirigée par Jean Garrigues chez Armand Colin, s'enrichit de ce recueil des "grands discours" de la Révolution française, choisis et présentés par Guy Chaussinand-Nogaret. Cette entreprise éditoriale a pour vocation, non seulement de proposer à un large public un corpus de textes souvent méconnus, mais aussi de faire redécouvrir ce que furent, en France, les moments et les "pères fondateurs » d'une démocratie parlementaire qui puise ses origines (toujours glorieuses!) dans le vivier de l'éloquence politique. Au fil de la quarantaine de textes proposés (de la transformation des états généraux en Assemblée nationale à la mise en place de la Convention thermidorienne), il s'agit de rappeler les grandes avancées de la politique révolutionnaire (sur le divorce, l'esclavage, l'instruction publique...) et, à travers les discours des principaux acteurs (Mirabeau, Barnave, Vergniaud, Robespierre), de célébrer le "grand cycle oratoire » d'une Révolution dont l'histoire serait toute entière rythmée par le déploiement de l'éloquence politique à "vocation universelle». Opposant ainsi la "sécheresse » et la fadeur des débats politiques contemporains à la "force", au "souffle» et à la "puissance» de la rhétorique révolutionnaire, G. Chaussinand-Nogaret exalte, parfois de manière naïvement touchante, les grands "athlètes du discours", ces hommes "désintéressés ", "très jeunes et ardents", « novices sans expérience » qui surent utiliser les ressources de la rhétorique et de l'art 
de la parole pour «faire triompher les idées de justice, de liberté et d'harmonie pour lesquelles ils combattaient». Certes, sans doute devrait-on se contenter de regretter (encore) que ce type d'ouvrage "grand public » soit rédigé - et cautionné - par un historien qui ignore - et fait fi dans une bibliographie autant partielle que partiale - des contributions historiographiques les plus récentes aussi bien sur l'étude du discours que sur les débats et les dynamiques des luttes politiques. Mais, alors que depuis plusieurs années est mené un travail érudit et sérieux sur la publication des archives parlementaires de la période révolutionnaire, on ne peut que dénoncer avec la plus grande vigueur la publication d'un tel ouvrage. Il ressort en effet des quelques pages d'introduction et de présentation rédigées par $\mathrm{G}$. Chaussinand-Nogaret des prises de position qui, aussi anachroniques soient-elles (Rivarol n'est souvent pas loin!), n'en dévoilent pas moins une lecture pour le moins très contestable de la Révolution française. La valorisation, idéalisée mais faussement naïve, de l'éloquence politique aboutit, d'un côté, à une décontextualisation, et de l'autre, à une dématérialisation du discours d'assemblée. Que dire pourtant du rôle des tribunes et du "public», des interruptions ou des acclamations, qui jouent un rôle essentiel dans les débats? Doit-on s'en tenir, comme le fait $\mathrm{G}$. Chaussinand-Nogaret, à affirmer l'efficacité performative sui generis des discours? Or, en réduisant l'histoire de la Révolution au jeu de la parole qui se déploie sur une scène de théâtre, il devient possible de présenter de manière manichéenne les luttes et les conflits qui dépassent largement les contours de l'Assemblée : la Constituante et ses "athlètes du discours ", érigés en véritables héros oratoires, deviennent les symboles de la «bonne » Révolution, un moment où le combat en faveur des libertés est assimilé à l'art maîtrisé, raisonnable et mondain, d'une rhétorique politique dont la "puissance» assurerait une diffusion universelle et garantirait la "révélation »! Naturellement, puisant ici dans les écrits des ennemis de la Révolution, G. Chaussinand-Nogaret introduit le thème de la «mauvaise » Révolution, celle de la violence et des tueries, période pendant laquelle des «intrigants», des « dictateurs » auraient détourné les ressources de l'éloquence pour servir leurs intérêts et alimenter les plus viles " passions " : la radicalisation politique et les violences qui lui sont liées sont ainsi réduites à un "glissement " de l'éloquence puisque "d'art de persuasion, elle devint un instrument d'extermination »... Nous touchons ici du doigt la véritable vocation de cet ouvrage qui participe à la (re)construction d'une «légende noire» de la Révolution qu'il convient, malheureusement encore, de prendre au sérieux: "Avec Robespierre, Saint-Just, Couthon, l'éloquence garda ses mérites littéraires, mais devint perfide, cruelle, terroriste ; elle devint un exercice d'intrigue et de délation "... Alors que l'ouvrage se trouve en bonne place sur les «tables» des grandes librairies, on ne saurait que regretter qu'une maison d'édition comme Armand Colin choisisse, pour alimenter son catalogue, de se tourner vers des « historiens » qui oublient les règles élémentaires du métier, pensant sans doute gagner quelque réputation auprès de lecteurs non avertis. 